\title{
Brief Analysis on Artistic Form of the Renaissance Period and the Baroque Period
}

\author{
Yelu Zhang \\ School of Art, Henan Institute of Education, Zhengzhou Henan, 450046, China
}

Keyword: Renaissance, Baroque, Artistic Form, Comparative Analysis.

\begin{abstract}
The Renaissance Period and The Baroque Period are two important artistic periods in the western art history. These two periods are close to each other in time, but having some differences in the artistic style. Artistic form has always been one important component of art. This paper makes comparative analysis on these two styles from the aspect of artistic form, which is convenient for us to deeply understand these two artistic forms and explore the development rule of the art.
\end{abstract}

\section{Radiating Artistic Peak--Brief Introduction to Artistic Style in the Renaissance Period}

Renaissance, Rinascimento in Italian, originally refers to the rebirth of classical literature and art. It is the cultural movement occurring from $14^{\text {th }}$ century to $16^{\text {th }}$ century, which originated from Florence, Milan and Venice in late Middle Ages, and then expanded to all European countries. By taking the renaissance of classical art as the starting point, it involves science, culture, economy and even the entire society and thoughts of human beings. Following after the art of Ancient Greece and Rome in the western art history, it is another artistic peak, which occupies a crucial position in the western art history and has huge influence on the art later.

Renaissance is not merely one artistic movement, but more cultural movement. It involves a lot, including science, literature ans economy, except for art. Therefore, artists in this period were usually "versatile", who did the painting in the meanwhile of studying science, especially DaVinci enjoying the reputation as "Three Great Masters of Renaissance". Not only one great master in the aspect of art, he made many achievements in anatomy, mechanics, biology, physics, hydraulics and architecture. During that historical period, the painting focused on: 1 . How to really show the nature; 2 . How to let the two-dimensional painting be three-dimensional, let the principle figure become vivid and let people take art as the portrayal of real life. Consequently, researches on perspective science and anatomy became the major subjects of artists at that time. How to show the sense of space, sense of depth and the real feelings of human in their products seemed to be one fashion and tide of the painting. Such as The Last Supper of DaVinci, it is taken from the story of Bible. However, the Bible does not specifically mention that the context where the story happens is within the room. While painting, DaVinci endowed the painting with an interior background with sense of depth. Moreover, the technique of manifestation was so splendid that people even had illusions. An inch was just as long as thousands of miles, which was affected by the popular painting style at that time. Some artists even considered the perspective science as the only theme of painting, such as the artistic master of Florence Paolo Uccello, in The Battle of San Romano, every weapon, armor and even line are strictly in accordance with the principle of perspective science. Just because of the mechanical painting style, this product seems stiff, without any vitality.

\section{Magnificent Passion--Brief Introduction to the Baroque Artistic Style}


The art of Baroque originated in the late $16^{\text {th }}$ century and became quite popular in $17^{\text {th }}$ century. Except for Northern Europe and Middle Europe, it gradually became declined in $18^{\text {th }}$ century. There are different versions of its origin. One says the art of Baroque originated from Portugal or Span, referring to non-round bead; another says it derived from Italian, referring to uniqueness, oddness or wrong deduction. Generally speaking, it is derogatory, which is the artistic style of the last century named by the classical art theorists of $18^{\text {th }}$ century. In short, the art is not worthy of being admired because it is strange, excessively carved and unique.

The Baroque Art was quite admired by the authority in $17^{\text {th }}$ Europe. At that time, so-called authority referred to the integration of church, feudal royalty and aristocratic. They had the same hobbies, loving magnificence, brilliance and extravagance. Of course, there was also most important point, they hoped the public absolutely obeyed the religion with the loyal belief. They were the richest class at that time, thus they could sponsor artists and require them to create artistic products according to their own wills. Based on those reasons, it is not hard for us to imagine the artistic styles of Baroque: first of all, it is luxury, which possesses the feature of religion and the color of hedonism; secondly, it is one passionate art, which breaks through the reasonable tranquility and harmony, possesses quite strong romantic colors and focuses on the rich imagination of artists; thirdly, it extremely focuses on motion. Motion and change can be considered as the soul of Baroque Art; fourthly, it has strong religious color. The religious theme has a dominant position in the Baroque Art.

\section{Comparative Analysis between the Artistic Form in The Renaissance Period and The Baroque Period}

As the style analysis, it can be explored from different perspectives. For instance, it can explore the differences of these two styles from the perspective of theme, ideology and manifestation pattern. Because artistic styles of the Renaissance and the Baroque came one after another, differences of theme and ideology are apparent. Of which, there are some comparisons. However, after all, they are under different backgrounds of times. Comparison in the aspect of theme and ideology seems quite far-fetched. However, the comparison in the aspect of manifestation pattern has quite important significance for exploring the changes of artistic forms. Besides, the artistic forms of these two styles have generated huge influences on the art later. Next, in view of artistic form, we will make a quite detailed comparative analysis on these two styles.

1. In view of paintings, products in the Renaissance Period emphasize on sketch, dominated by line modeling. However, products of Baroque style emphasize on color, dominated by light\&shade style. Sketch and color are two major manifestation means of painting. No matter paintings in the Renaissance Period or Baroque Period, sketch and color are essential elements. Here, to focus on sketch or color, it is relative. From the paintings of Renaissance Period, we can discover that, sketch line has a quite important modeling position. Due to the emphasis on lines, every figure in the paintings of Renaissance Period has quite clear outline. There is also a quite clear boundary line between objects. In this way, every figure has one independent color and creation. Meanwhile, colors applied to show figure and object are not quite rich. As the character image, although there are changes of light and shade, the application of color is just limited to show the light and shade, without its own characteristics. In the paintings of the Baroque Period, color is promoted to a quite crucial position. In products, contour lines of figure and object are obscure, lines give way to colors. Figure relationship and object relationship are understood as the relationship between color lumps, light and shade. It is not the pure outline of line. Figures in the painting are not colored independently, but integrated with each other. According to the light and shade, it makes the description. The major subject is depicted finely under bright light. Figure and object are obscure in darkness. In this way, it greatly reinforces the vivid sense of three-dimensional and sense of reality(That's because everything in the real life actually has no boundary line). Meanwhile, we can also see that, paintings of the Baroque Period quite finely and richly show the colors. In the products of the representative Rubens, due to the rich color and delicate presentation, the female body is no longer cold painting or as far as the statue. It seems that they are real, flesh and blood, standing in front of viewers. 
As a matter of fact, changes in form reflects one transition of internal spirit. In the Renaissance Period, humanism spirit is the core of this movement. To focus on human-oriented and wakening self-awareness, it undoubtedly requires people to abandon the original ignorance and stupidness, so as to begin believing in rationality and science. Manifestation techniques of painting are just closely related to science, including sketch, perspective and anatomy. In the paintings of The Renaissance Period, artists use lines to sketch the contours of figures abstemiously. Colors are firmly locked within the contour, which is just the presentation of rationality and self-discipline. Because the Baroque Art serves the religion and bigwigs, it does not like such rational abstinence and self-discipline. The religion and bigwigs want to see a resplendent, magnificent and luxury world. Promoted by such an idea, artists of the Baroque Period focused on representing the sensual feelings brought by the objects more delicately, who did not want to master the technique of representing the real world, further to show the scientific humanity. Just because of the ideological changes, it brought the transition from emphasizing on sketch to color. It should be noted that, such a change did not happen overnight. At the end of The Renaissance Period, contributions of Venetian school also offered quite a lot inspirations for the artists in the Baroque Period. Meanwhile, artists of the Renaissance Period studied the manifestation techniques of painting, which laid a solid foundation for the artistic creation of artists in the Baroque Period. No matter how they focused on expressing colors, the basic perspective, anatomy principle and sketch foundation were essential. At that time, they would at least neither worry about how to depict a three-dimensional space, nor dissect corpse by themselves in order to understand the anatomical structure of human bodies.

2.No matter the statue or painting, from the perspective of composition, products of the Renaissance Period apply the "closed" composition mode, which are set up above the perpendicular line and horizontal line. Such a mode brings a peaceful, tranquil and balanced feeling; products of the Baroque Period apply the "open” composition mode, which brings strong dynamics and insurgent passion. We make a comparison between David of Michelangelo(enjoying the reputation of "Three Great Masters of Renaissance") and David of Bernini (chief of Italian Baroque Art), the differences of these two styles are apparent.

In David of Michelangelo, we can feel one tranquil strength and that "noble purity, solemn greatness". Such a sense of tranquility comes from upright trunk and elegant posture. It is a closed composition mode. The reason why it is called the closed composition, that's because the product is independent in such a composition, the viewers are not involved in the product. We quite clearly feel that it is one sculpture in front of us, which has no great relation to us. However, in David of Bernini, we see strongly distorted body. Movements are not that elegant. The sling is not grasped in hand steadily, but shooting the audiences. In such a composition, audiences are invited to products, which seem to be part of this product. It seems that you are the giant to be knocked down by David. Obviously, such a composition mode cannot be enclosed, which invites more people to participated in the product. Therefore, we call it as the open composition. Such a composition is dynamic, not still, which has greater appeal, highlights motion and enthusiasm. Character images are more real and perceptible.

3.From the relation between the whole and parts, artistic products of the Renaissance Period are characterized by "composability", which means every image is independent. The overall image is harmoniously composed by every independent image; the artistic products of the Baroque Period are characterized by "integration”, which means every image is integrated with each other, echoing and organically composing one integrity.

We make a detailed comparison between the School of Athens of Raphael and The Night Watch of Rembrandt.

Two products are the large paintings composed of numerous figures. In the School of Athens of Raphael, every part possesses statuesque stereoscopic impression. Every part is filled in by its own, single and partial color. However, in The Night Watch of Rembrandt, all units are connected as an integrity, no single unit can be separated. As the mix and combination of color, and their appearance, they mainly depends on how they are covered by the light. For instance, in the foreground, only part 
of the spear pointing at us is golden, other parts are gray black because of the shadow projection. In the products of Rembrandt, strong and unidirectional light makes all units correlate to each other, which mixes those local colors. However, in the paintings of Raphael, there are no changes of light or color. Light is injected into the scene by even diffusion. Such light isolates all parts in the painting from each other, which makes a lot of independent units keep balance.

After analyzing these two styles from different perspectives in details, we can also discover that differences of theses styles are not isolated, but connecting with each other. For instance, line modeling must bring the composition effect to the scene, the color modeling strengthens the integration of scene; the closed composition and two-dimensional level supplement each other. The recessive progressive hierarchy can also strengthen the picture effect of open composition. As understanding about any style cannot be isolated or unilateral. Any style cannot merely composed of one form.

\section{Conclusion}

Artistic styles of both The Renaissance Period and The Baroque Period have produced huge impact on the western art afterwards. For instance, art of The Neoclassical Period has many artistic characteristics of the Renaissance Period, that of Romanticism has many characteristics of The Baroque Period. Emphasis on sketch and color, rationality and passion have become the important contradictory relation of the art development. It is hoped that detailed analysis on form can help us to recognize the concrete manifestation pattern of these contradictions. Moreover, by analyzing artistic forms of these two styles, it can strengthen our understandings about artistic forms similar to that.

\section{Reference}

[1] Peng Ya , History of Foreign Art, Henan University Press, 2003.

[2] Teaching and Research Office of History of Department of Art History Foreign Art of Central Academy of Fine Arts, Brief Introduction to Foreign Art, Higher Education Press, 2006.

[3] [America] Rudolf Arnheim, Art and Visual Perception, China Social Sciences Publishing House, 1984.

[4] [Britain] Gombrich, The Story of Art, People's Fine Arts Publishing House, 2003. 